\title{
Crystal structure of human arginase I complexed with thiosemicarbazide reveals an unusual thiocarbonyl $\mu$-sulfide ligand in the binuclear manganese cluster
}

\author{
Luigi Di Costanzo, Michael E. Pique, and David W. Christianson ${ }^{*}$ \\ Roy and Diana Vagelos Laboratories, Department of Chemistry, University of Pennsylvania, \\ Philadelphia, Pennsylvania 19104-6323, and The Scripps Research Institute MB-5, 10550 North \\ Torrey Pines Road, La Jolla, CA 92037
}

\begin{abstract}
The crystal structure of the human arginase I-thiosemicarbazide complex reveals an unusual thiocarbonyl $\mu$-sulfide ligand in the binuclear manganese cluster. The $\mathrm{C}=\mathrm{S}$ moiety of thiosemicarbazide bridges $\mathrm{Mn}^{2+} \mathrm{A}$ and $\mathrm{Mn}^{2+} \mathrm{B}$ with coordination distances of $2.6 \AA$ and $2.4 \AA$, respectively. Otherwise, the binding of thiosemicarbazide to human arginase I does not cause any significant structural changes in the active site. The crystal structure of the unliganded enzyme reveals a hydrogen bonded water molecule that could support proton transfer between a $\mu$-water molecule and H141 to regenerate the nucleophilic $\mu$-hydroxide ion in the final step of catalysis.
\end{abstract}

Arginase is a $105 \mathrm{kDa}$ homotrimer containing a binuclear manganese(II) cluster in each subunit required for the hydrolysis of L-arginine to yield L-ornithine and urea. ${ }^{1}$ Two isozymes, arginase I and arginase II, have been identified in humans and the amino acid sequences of these isozymes are related by $60 \%$ identity. In recent years, increasing attention has focused on arginase as a potential therapeutic target due to the overexpression of these isozymes in a variety of diseased tissues and organs, e.g., the airway of asthma patients ${ }^{2}$, the spinal cord fluid in an animal model of multiple sclerosis ${ }^{3}$, and the corpus cavernosum of diabetic men suffering from erectile dysfunction. ${ }^{4}$

The first X-ray crystal structure of an unliganded mammalian arginase was that of rat arginase I, which revealed a $\mathrm{Mn}^{2+}-\mathrm{Mn}^{2+}$ cluster bridged by a nonprotein ligand interpreted as a $\mu$ hydroxide ion that functions as a nucleophile in catalysis. ${ }^{5}$ The subsequently determined structure of rat arginase I complexed with the boronic acid substrate analogue 2(S)-amino-6boronohexanoic acid $(\mathrm{ABH})^{6}$ revealed the binding of the tetrahedral boronate anion form of the inhibitor, which mimics the tetrahedral transition state. ${ }^{7}$ Recently determined crystal structures of human arginases I and II complexed with $\mathrm{ABH}$ and/or the related boronic acid substrate analogue $S$-(2-boronoethyl)-L-cysteine (BEC) ${ }^{8}$ revealed similar inhibitor binding modes. 9,10

Despite the high affinity of ABH binding to human arginase $\mathrm{I}\left(\mathrm{K}_{\mathrm{d}}=5 \mathrm{nM}\right)^{10}$, consideration of $\mathrm{ABH}$ as a possible drug candidate for the treatment of human diseases linked to arginase hyperactivity is tempered by the relative scarcity of boron-containing drugs. ${ }^{11}$ Thus, we have continued to explore new functional groups for manganese coordination in the design and development of new arginase inhibitors. We now report the X-ray crystal structure of human arginase I complexed with thiosemicarbazide determined at $1.95 \AA$ resolution. 
For structure determination, human arginase I was overexpressed in E. coli, purified, and crystallized as described 10,12 with the exception that the protein solution contained $1.4 \mathrm{mM}$ thiosemicarbazide. The structure was refined to final $\mathrm{R}_{\text {twin }}$ and $\mathrm{R}_{\text {free/twin }}$ values of 0.169 and 0.219 , respectively. The structure of unliganded human arginase I was also determined at 1.90

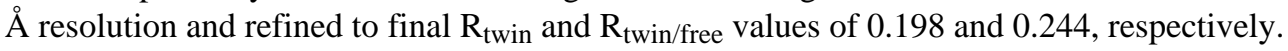
Complete experimental details are reported in the Supplementary Information.

The root-mean-square (r.m.s.) deviation of $314 \mathrm{C} \sigma$ atoms between unliganded rat arginase I and unliganded human arginase $\mathrm{I}$ is $0.64 \AA$, indicating that these enzymes are quite similar in structure (as expected by their amino acid sequence identity of $87 \%$ ). However, interesting differences are evident in active site solvent structure and appear to result from an alternative conformation of T246: in human arginase I, the T246 hydroxyl group of this residue is oriented towards the manganese ions and forms a hydrogen bond with solvent molecule \#76, which in turn forms a hydrogen bond with the metal-bridging hydroxide ion (solvent molecule \#119); in rat arginase I, the T246 hydroxyl group is oriented away from the manganese ions (Figure $1)$.

Interestingly, the metal-bridging hydroxide ion is also within hydrogen bonding distance of solvent molecule \#211, which also forms a hydrogen bond with H141. Solvent molecule \#211 also interacts weakly with $\mathrm{Mn}^{2+}{ }_{\mathrm{A}}$, but the $\mathrm{Mn}^{2+} \mathrm{A}^{-} \mathrm{O}$ separation of $2.8 \AA$ is too long to be considered an inner-sphere coordination interaction. That solvent molecule \#211 forms a hydrogen bonded bridge between the metal-bridging hydroxide ion and H141 is consistent with the proposed role of $\mathrm{H} 141$ as a proton shuttle in the regeneration of the nucleophilic metalbridging hydroxide ion from a metal-bridging water molecule. ${ }^{5}$ In other words, solvent molecule \#211 may serve as a "proton wire" to facilitate proton transfer in catalysis. 13

The binding of thiosemicarbazide to human arginase I does not cause any significant structural changes in the active site, and the r.m.s. deviation is $0.39 \AA$ for 313 C $\sigma$ atoms between the structures of the thiosemicarbazide-complexed and unliganded enzymes. However, a significant structural change is observed in the manganese coordination polyhedra: the $\mathrm{C}=\mathrm{S}$ moiety of thiosemicarbazide bridges $\mathrm{Mn}^{2+} \mathrm{A}$ and $\mathrm{Mn}^{2+} \mathrm{B}$ with coordination distances of $2.6 \AA$ and $2.4 \AA$, respectively (Figure 2). These metal coordination distances are consistent with other metalloprotein crystal structures. A search of the Protein Data Bank (PDB) ${ }^{14}$ retrieves 62 unique cysteine- $\mathrm{Mn}^{2+}$ interactions in 18 protein structures, 12 unique methionine- $\mathrm{Mn}^{2+}$ interactions in 6 protein structures, and 3 unique $\mathrm{S}-\mathrm{Mn}^{2+}$ interactions involving non-protein groups, e.g., thiophosphate derivatives. The average $\mathrm{S}-\mathrm{Mn}^{2+}$ coordination distance is $2.6 \pm 0.2$ $\AA$ for cysteine ligands and $2.8 \pm 0.1 \AA$ for methionine ligands. Additional geometric data are reported in Figure $\mathrm{S} 1$ of the Supporting Information.

Analyses of the PDB and the Cambridge Structural Database (CSD) ${ }^{15}$ indicate that the human arginase I-thiosemicarbazide complex is only the second crystal structure ever determined of a thiosemicarbazide complexed with $\mathrm{Mn}^{2+}$, the first such complex being aqua-2,2'-bipyridyl)(thiosemicarbazidediacetato-O, $\mathrm{O}^{\prime}, \mathrm{S}$ )-manganese(II) sesquihydrate (CSD accession code YARSEP) in which the manganese-sulfur coordination distance is $2.6 \AA .16$

Further analysis of the CSD (see Supporting Information) yields a total of 68 structures of thiosemicarbazide complexes with the following metal ions: Mn (1), Fe (3), Co (6), Ni (22), $\mathrm{Cu}$ (6), Zn (7), Rh (3), Ag (8), Cd (6), Pt (1), Hg (2), Pb (2), and Bi (1). The thiosemicarbazide $\mathrm{S}-\mathrm{C}-\mathrm{N}-\mathrm{N}$ dihedral angle is occasionally distorted in these structures, and out-of-plane deviations of up to $21^{\circ}$ are observed. At $64^{\circ}$, the distortion of the S-C-N-N dihedral angle of thiosemicarbazide bound to human arginase $\mathrm{I}$ is even more pronounced (Figure 2). This distortion appears to facilitate the formation of numerous direct and water-mediated hydrogen bonds. Comparable distortions of O-C-N-O dihedral angles are observed for N-hydroxyurea 
inhibitors of matrix metalloproteinases and may similarly be facilitated by intermolecular hydrogen bond interactions. 17

Given that the N-OH groups of N-hydroxy-L-arginine and N-hydroxy-nor-L-arginine displace the metal-bridging hydroxide ion of unliganded rat arginase $\mathrm{I},{ }^{18}$ it is surprising that the $\mathrm{N}$ $\mathrm{NH}_{2}$ group of thiosemicarbazide does not do likewise. It is especially surprising that the electron-rich sulfur atom of thiosemicarbazide is preferred for manganese coordination given the fact that the electron-rich sulfur atom of thiosemicarbazide is a relatively soft ligand and $\mathrm{Mn}^{2+}$ is a relatively hard metal ion. 19

Regardless, insofar that thiosemicarbazide is an analogue of urea, it is notable that this structure provides the first experimental evidence in support of a metal-bridging mode for the urea product as first proposed by Kanyo and collegues. ${ }^{5}$ The binding affinity of urea is weak $\left(\mathrm{K}_{\mathrm{d}}\right.$ $\sim 1 \mathrm{M})^{20}$, and isothermal titration calorimetry similarly indicates weak affinity for thiosemicarbazide with $\mathrm{K}_{\mathrm{d}}>0.1 \mathrm{mM}$ (i.e., beyond the detection threshold), so the $\mathrm{K}_{\mathrm{d}}$ value of thiosemicarbazide likely resides somewhere between these values. Nevertheless, we conclude that the unusual $\mathrm{C}=\mathrm{S}---\mathrm{Mn}^{2+}$ interactions shown in Figure 2 highlight the potential of thiosemicarbazide as a useful fragment ${ }^{21}$ for the design of amino acid thiosemicarbazide inhibitors that will be described in due course. 22

\section{Supplementary Material}

Refer to Web version on PubMed Central for supplementary material.

\section{Acknowledgements}

We thank the NIH for grant GM49758 and D.W.C. thanks the Sandler Program for Asthma Research for a Senior Investigator award. Finally, we thank Dr. Hyunshun Shin for suggesting the study of thiosemicarbazide and Prof. Franscisco Centeno for the gift of the human arginase I plasmid.

\section{References}

1. Christianson DW. Acc Chem Res 2005;101:191-201. [PubMed: 15766238]

2. Zimmermann N, King NE, Laporte J, Yang M, Mishra A, Pope SM, Muntel EE, Witte DP, Pegg AA, Foster PS, Hamid Q, Rothenberg ME. J Clin Invest 2003;111:1863-1874. [PubMed: 12813022]

3. Xu L, Hilliard B, Carmody RJ, Tsabary G, Shin H, Christianson DW, Chen YH. Immunology 2003;110:141-148. [PubMed: 12941151]

4. Bivalaqua TJ, Hellstrom WJ, Kadowitz PJ, Champion HC. Biochem Biophys Res Commun 2001;283:923-927. [PubMed: 11350073]

5. Kanyo ZF, Scolnick LR, Ash DE, Christianson DW. Nature 1996;383:554-557. [PubMed: 8849731]

6. Baggio R, Elbaum D, Kanyo ZF, Carroll PJ, Cavalli RC, Ash DE, Christianson DW. J Am Chem Soc 1997;119:8107-8108.

7. Cox JD, Kim NN, Traish AM, Christianson DW. Nat Struct Biol 1999;6:1043-1047. [PubMed: 10542097]

8. Kim NN, Cox JD, Baggio RF, Emig FA, Mistry SK, Harper SL, Speicher DW, Morris SM Jr, Ash DE, Traish A, Christianson DW. Biochemistry 2001;40:2678-2688. [PubMed: 11258879]

9. Cama E, Colleluori DM, Emig FA, Shin H, Kim SW, Kim NN, Traish AM, Ash DE, Christianson DW. Biochemistry 2003;42:8445-8451. [PubMed: 12859189]

10. Di Costanzo L, Sabio G, Mora A, Rodriguez PC, Ochoa AC, Centeno F, Christianson DW. Proc Natl Acad Sci 2005;102:13058-13063. [PubMed: 16141327]

11. Robertson JG. Biochemistry 2005;44:5561-5571. [PubMed: 15823014]

12. Mora A, del Ara Rangel M, Fuentes JM, Soler G, Centeno F. Biochim Biophys Acta 2000;1476:181190. [PubMed: 10669784] 
13. a) Cui Q, Karplus M. J Phys Chem 2003;B107:1071-1078. (b) Lu D, Voth GA. J Am Chem Soc 1998;120:4006-4014. (c) Xu J, Voth GA. Proc Natl Acad Sci 2005;102:6795-6800. [PubMed: 15857953]

14. Berman HM, Westbrook J, Feng Z, Gilliland G, Bhat TN, Weissig H, Shindyalov IN, Bourne PE. Nucleic Acids Res 2000;28:235-242. [PubMed: 10592235]

15. Allen FH. Acta Cryst B 2002;58:380-388. [PubMed: 12037359]

16. Simonov YA, Lozan VI, Kravtsov VK, Gerbeleu NV, Bologna OA, Malinovskii TI. Zh Neorg Khim (Russ J Inorg Chem) 1992;37:1519-1524.

17. Campestre C, Agamennone M, Tortorella P, Preziuso S, Biasone A, Gavuzzo E, Pochetti G, Mazza F, Hiller O, Tschesche H, Consalvi V, Gallina C. Bioorg Med Chem Lett 2006;16:20-24. [PubMed: 16242329]

18. Cox JD, Cama E, Colleluori DM, Pethe S, Boucher JL, Mansuy D, Ash DE, Christianson DW. Biochemistry 2001;40:2689-2701. [PubMed: 11258880]

19. Among the first row transition metals, the $\mathrm{Mn}^{2+}$ ion is relatively "hard" yet is thiophilic in comparison with the "harder" $\mathrm{Mg}^{2+}$ ion; see (a) Reed GH, Poyner RR. Met Ions Biol Syst 2000;37:183-207. [PubMed: 10693135] (b) Crowley JD, Traynor DA, Weatherburn DC. Met Ions Biol Syst 2000;37:209-278. [PubMed: 10693136]

20. Reczkowski RS, Ash DE. Arch Biochem Biophys 1994;312:31-37. [PubMed: 8031143]

21. Hajduk PJ, Greer J. Nature Rev Drug Discov 2007;6:211-219. [PubMed: 17290284]

22. The atomic coordinates of the human arginase I-thiosemicarbazide complex and unliganded human arginase I have been deposited in the Protein Data Bank with accession codes 2PHO and 2PHA, respectively. 


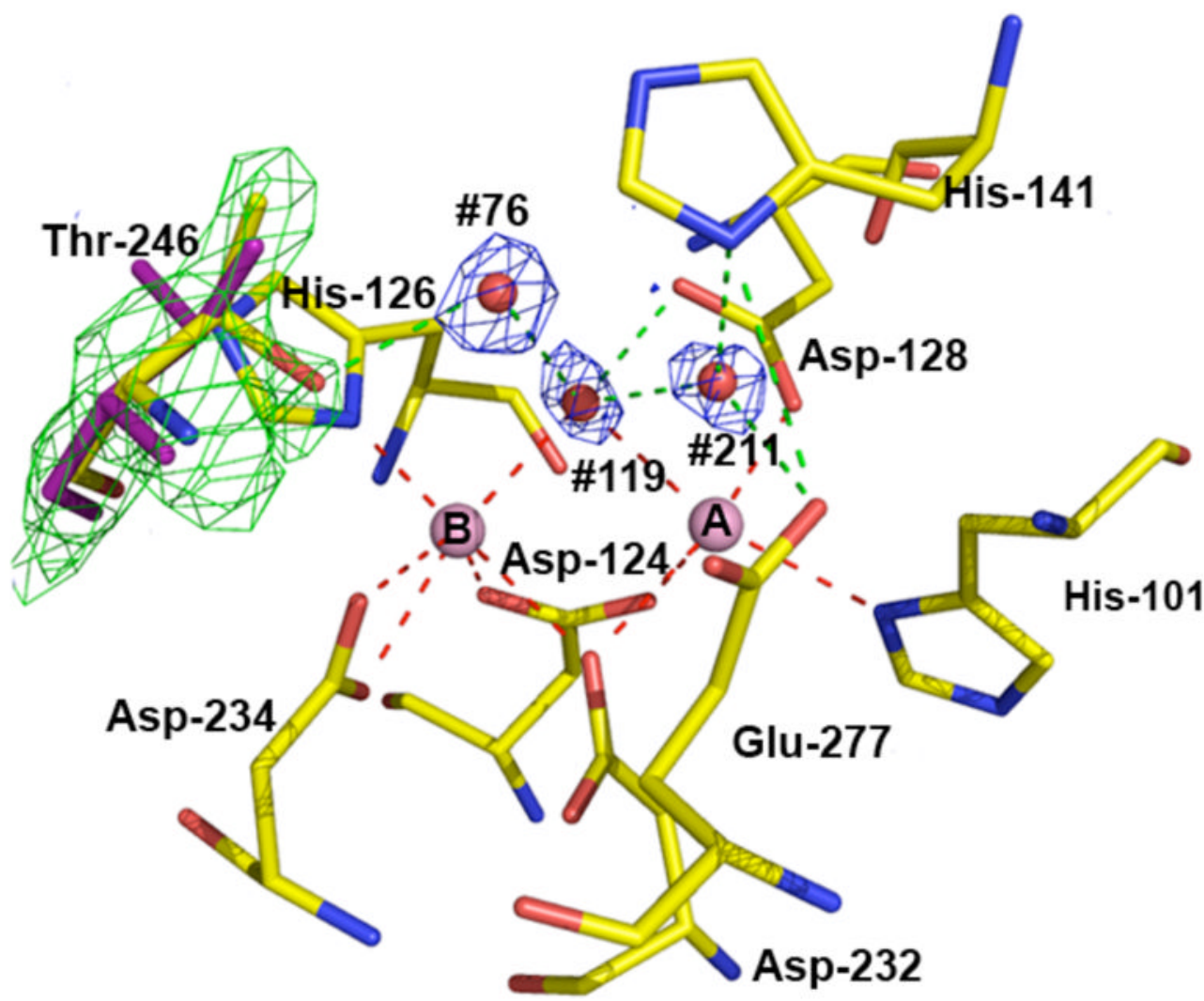

Figure 1.

Omit electron density map of unliganded human arginase I calculated with Fourier coefficients $\left|\mathrm{F}_{\mathrm{obs} / \mathrm{A}}\right|-\left|\mathrm{F}_{\mathrm{calc}} / \mathrm{A}\right|$ for twin domain $\mathrm{A}$ and phases from the refined enzyme model less the atoms of T246 (contoured at 2.7б, green) and water molecules \#76, \#119 and \#211 (contoured at $3.0 \sigma$, blue). The T246 conformation in rat arginase I (magenta) is superimposed. 

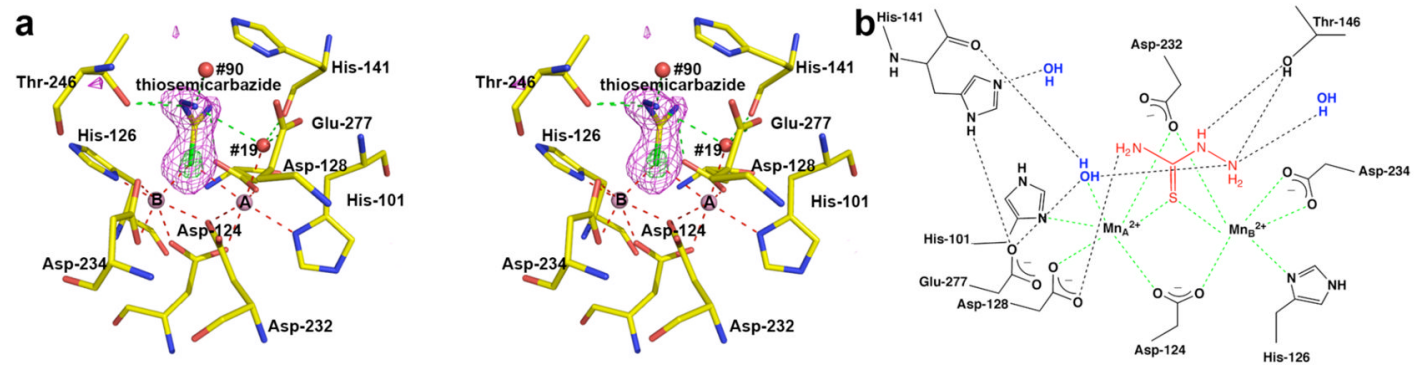

Figure 2.

(a) Stereoview of simulated annealing gradient maps showing thiosemicarbazide ( $3.1 \sigma$ contour, magenta) and its electron-rich sulfur atom ( $7.3 \sigma$ contour, green) bound to human arginase I. Dashed lines indicate manganese coordination (red) and hydrogen bond (green) interactions. Atom color codes: carbon (yellow), oxygen (red), nitrogen (blue), manganese (pink), sulfur (green). (b) Summary of intermolecular interactions. 